\title{
Extended Validation Study of the Thinking and Creative Style Scale: Development of a Shorter Version
}

\author{
Solange Muglia Wechsler ${ }^{1}$ \\ Pontificia Universidade Catolica de Campinas \\ Barbara M Byrne \\ University of Ottawa
}

\begin{abstract}
There are several measures of cognition and creative styles, however few of them are valid and short enough to be administered in different settings. Therefore, this study had two purposes: to reanalyze and obtain validity evidence of the Scale of Thinking and Creative Scale (STCS), developed by Wechsler, measuring five styles, based on a progression of increasingly rigorous exploratory and confirmatory factor analytic procedures, and (b) to provide a viable psychometrically sound short version of this scale. Based on a sample of 1,752 Brazilians (55\% women; ages 14 to 70 ) living in four states (93\% from Sao Paulo), results strongly supported five dimensions of thinking and creative style, thus indicating the validity and reliability of the abridged STCS version.
\end{abstract}

Keywords: psychological assessment, styles, creativity, validity, factor

\section{Ampliação do Estudo de Validação da Escala Estilos de Pensar e Criar: Desenvolvimento de uma Versão Reduzida}

\begin{abstract}
RESUMO - Existem várias medidas de estilos de pensar e criar, porém poucas são validadas e suficientemente curtas para administração em diferentes ambientes. Portanto, este estudo teve dois objetivos: (a) reanalisar e validar a Escala de Estilos de Pensar e Criar, desenvolvida por Wechsler, que mede cinco estilos, baseando-se em uma progressão de procedimentos estatísticos rigorosos de análises fatorial exploratória e confirmatória; (b) propor uma versão reduzida dessa escala, atendendo aos parâmetros psicométricos. Baseando-se em amostra de 1.752 brasileiros (55\% mulheres, idades $14-70$ anos) vivendo em quatro estados (93\% de SP), os resultados demonstraram que existem cinco dimensões dos estilos de pensar e criar, que podem ser medidos de forma válida e precisa por meio de uma versão reduzida desta escala.
\end{abstract}

Palavras-chave: avaliação psicológica, estilos, criatividade, validade, fator

The concept of styles has instigated debates among researchers over the last 4 decades, thus demonstrating its importance for understanding individual differences (Nielsen, 2012). Styles can be defined as preferred ways of thinking and behaving, thus encompassing cognitive processes as well as personality characteristics (Kaufman \& Baer, 2005; Rayner \& Peterson, 2009; Sternberg \& Grigorenko, 2001). Given that styles are processes that can be distinguished from abilities it is not possible to assess them through right or wrong answers as they involve higher-order strategies rather than task specific ones (Isaksen, Wilson, \& Lauer, 2003; Zhang, Sternberg, \& Rayner, 2012). There have been many attempts to integrate the different perspectives on styles, thereby reaffirming the need to move toward a global theory in order to comprehend the contribution that the concept of styles can bring to various domains such as creativity, teaching and learning (Casssidy, 2004; Zhang, 2013).

In his review of the literature spanning the past 40 years, Nielson (2012) observed that the term "styles" has tended to be used mostly with respect to cognitive and learning styles.

1 Endereço para Correspondência: Pontifícia Universidade Católica de Campinas, Pós-Graduação em Psicologia, Campus II, Av. John Boyd Dunlop, s/n, Campinas, São Paulo, Brasil. CEP: 13.060-904. E-mail: wechsler@lexxa.com.
Cognitive styles are defined as individual differences in processing information and are considered to be partly fixed, relatively stable and possibly representing innate preferences (Peterson, Rayner, \& Armstrong, 2009). Several recently proposed models have attempted to explain the nature of cognitive styles based on genetic etiology (Grigorenko, 2009), physiological or sensory preferences (Miller, 2001), and/or as a function of personality traits or types comparable to the Myers-Briggs or Cattell's assessment scales (Isaksen, Kaufman, \& Bakken, 2014; Roodenburg, 2003). An integrated theory, grounded in a biopsychosocial approach, was proposed by Zang and Sternberg (2006) in which they termed intellectual styles as the preferred way of processing and dealing with tasks resulting from a combination of cognitive, affective, physiological, psychological, and sociological characteristics.

In contrast to cognitive and learning styles, creative styles are considered to represent preferred ways of expressing creative potential and/or, understanding creativity as a multidimensional phenomenon that results from the interaction of cognitive processes, personality variables and cultural environments (Csikszentmihalyi, 2009; Hennessey \& Amabile, 2010; Torrance, 1988; Sternberg \& Lubart, 2009). As such, the individual's contribution to a specific group must 
be original and effective before it can be considered creative (Runco \& Jaeger, 2012). To better understand creativity, it is important to separate levels (ability, potential) and styles (modality, preferences). Levels are typically measured using tests of divergent thinking, such as the Torrance tests of creativity, whereas styles are more appropriately measured by a test of process and attitudes (Isaksen, 2004; Sternberg, Grigorenko, \& Singer, 2004).

Measures of creative styles have focused on either cognitive or on personality dimensions. Kirton (1999) classified cognitive styles as having two major dimensions - that of innovator (i.e., seeking change) and that of adapter (i.e., seeking implementation). These styles are considered to be stable and represent components of personality (Kirton,1989). Other measures of creative styles have associated them with problem-solving strategies. For example, the instrument designed to measure leadership and creative styles, proposed by Puccio, Murdock and Mance (2007), included four types of styles: the clarifier, the ideator, the developer and the implementer, while considering some of these styles related to temperament and others to personality. In contrast, the View instrument by Selby, Treffinger, and Isaksen (2007), is composed of three dimensions - orientation to change (developer or explorer style), manner of processing information (external or internal style), and preferences for making decisions (people or task focused style).

Assessment of creative styles through personality characteristics are also found in other measures. For example, Wechsler's Scale of Thinking and Creative Styles-STCS (Wechsler, 2006) resulted from a synthesis of 25 personality characteristics investigated in a Brazilian sample. The results obtained from principal components analyses (PCA) indicated the following styles: 1) Cautious-Reflexive; 2) Nonconforming-Innovative; 3) Logical-Objective; 4) EmotionalIntuitive; 5) Relational-Divergent). The first two styles were found to be related to Kirton's Innovative-Adaptative model when analyzed through Item response theory based on the Rash Model (Wechsler, Vendramini, \& Oakland, 2012). However, different dimensions of these styles have been observed in samples from other cultures. In the Madeira Islands, although factor analytic results failed to identify the first style, the remaing four styles were identified (Garces, Pocinho, Wechsler, \& Jesus, 2014). More recently, another study with samples from Lisbon (Nogueira, Almeida, Garces, Pocinho, \& Wechsler, 2015), using confirmatory factor analysis (CFA), indicated the existence only of the first three creative styles. Although these results suggest that particular creative styles may not be important in another culture, the question is raised as to the dimensions for which creative styles can be assessed and/or expressed.

The identification of creative and thinking styles is relevant for educational (Alencar \& Fleith, 2016; Nakano, Santos, Zavariz, Wechsler, \& Martins, 2010) as well as organizational settings (Mundim \& Wechsler, 2007). However, measuring creative styles remains a challenge as the majority of assessments takes considerable time and relies on self-reports. Therefore, there is the need for shorter instruments in these settings that also fulfill the criteria of reliability and validity in accordance with international standards (American Educational Research Association
[AERA], the American Psychological Association [APA], National Council of Measurement in Education [NCME], 2014). Evidence of validity can be based on an assessment scale's factorial structure (i.e., internal validity), or on its relation to other criterion measurement scores within the framework of the same nomological network (i.e., external validity). Ideally, it should be based on both forms of validity. This requirement appears not to have been fulfilled with respect to the measurement of styles. Indeed, based on their review of 13 styles instruments, Coffield, Moseley, Hall, and Ecclestone (2004) found evidence of internal validity to be one of the weakest criteria reported. Furthermore, Cools (2009) contends that most studies of styles have been conducted based on comparison with other existing measures. Pointing to the weakness of scales designed to measure styles, Cassidy (2004) concluded that the field is still very much in its infancy.

Clearly, a review of the styles literature yields unquestionable evidence for the need of a rigorously tested and validated measurement scale that is grounded in theory. The STCS is a long instrument comprising 90 items that is in definite need of revision as a shorter version of this scale. The purpose of this study was therefore twofold: (a) to validate scores from the STCS based on a progression of increasingly rigorous EFA and CFA procedures; and (b) to propose a viable psychometrically sound short version of the STCS.

\section{Method}

\section{Sample}

The sample upon which these analyses were based comprised 1,752 Brazilians (55\% women), ages 14 to 70 years $(M=24,5 ; S D 8,9)$ living in four states $(93 \%$ from Sao Paulo). All individuals had either high school or university undergraduate level education obtained from public or private universities and came mainly from middle class families.

\section{Procedure}

The research was previously approved by the institutional Ethical Committee of the Pontificia Universidade Catolica de Campinas, n.277/07. Individuals were contacted at the universities or in work settings and invited to complete the scale for research purposes. This was the sample on which the theoretical study was conducted.

\section{Instrument of Measurement}

The STCS consists of 90 Likert-scaled items meant to represent 25 well established concepts from the literature on creative personality characteristics. Four items were constructed for each concept. Devellis (2012) argues that the construction of multiple items related to the same content, although leading to possible redundancy, is advisable as one is attempting to capture the construct with different phrases. 
In addition, two items were positively related to the construct and two negatively related in order to avoid response acquiescence. The original results obtained from principal components analyses (PCA) indicated 5 styles: Factor 1 represented the cautious-reflexive style, that is individuals who are prudent and ponder their actions (example item: I feel lazy to find new things to do; Factor 2 indicated the non-conforming innovative style, preferred by those who are self-motivated and original thinkers (example item: I like to question and give suggestions); Factor 3, demonstrated the logical-objective style, that is, individuals who prefer to plan and act using structure before making decisions (example: I like to work following instructions) Factor 4, represented by emotional-intuitive style, that is, those persons who based on their feelings and inspirations to take actions (example: I make decisions based on my feelings); and Factor 5, demonstrated by the relational divergent style, demonstrated by those who listen to other group members and synthesize their views before making a decision (example: I like to listen to others'points of view before making decisions) These styles have been related to recognized creative production in real life achievements (Wechsler, 2006). Two styles (Cautious-Reflexive, Non-Conforming Innovative) were also found to be associated with the total score of the Figural and Verbal creativity indicators of the Torrance Test of Creative Thinking (Wechsler et al., 2012). Alpha reliability indexes for each factor were reported as. $968, .884, .816, .532, .518$ respectively.

\section{Statistical Analyses}

All analyses were based on the Mplus structural equation modeling (SEM) program, Version 7.3 (Muthén \& Muthén, 1998-2012). Pre-analytic screening of the data revealed three cases to have missing responses, and they were excluded, thereby reducing the sample size to 1,749 . In addition, investigation of the score distribution normality revealed some evidence of multivariate kurtosis. Thus, all analyses were based on the MLM estimator, which is robust to such non-normality and capable of making appropriate corrections to both the chi square statistic and the related goodness-offit indices.

Based on a three-way randomized grouping of the data, analyses were conducted in a series of four stages. First, based on Group1 data ( $n=583$ ), EFA was used to re-evaluate factorial structure of the STCS. Second, based on Group 2 data $(n=584)$, we used CFA to test the validity of a reduced 5 -factor structure comprising items that exhibited the strongest link with their related underlying latent factor in the EFA. Third, the final best-fitting CFA 5-factor structure determined for Group 2 was cross-validated based on Group 3 ( $n=582)$ using two different approaches: (a) comparisons were made regarding model goodness-of-fit for Group 3; and (b) all factor loadings and factor covariances of the final model were tested for their invariance across Groups 2 and 3. Finally, drawing on CFA findings related to the best-fitting 5-factor structure initially established for Group 2 and cross-validated for Group 3, we developed a rigorous and psychometrically sound shorter version of the STCS.

\section{Results}

Step 1. Exploratory Factor Analyses (Group 1; $\mathbf{n}=\mathbf{5 8 3}$ )

In contrast to original analyses of the STCS (Wechsler, 2006), we used EFA, rather than principal components analysis (PCA). Given many other critical distinguishing features between these two procedures, it is important to recognize that PCA should not be equated with EFA (see e.g., Fabrigar, Wegener, MacCallum, \& Strahan, 1999).

Based on Geomin oblique rotation and consistent with current theoretical perspectives, analyses tested a range of possible factor structures. As expected, findings clearly showed the 5-factor structure of the STCS to best fit the data for Group 1 (RMSEA $=0.035 ; \mathrm{SRMR}=0.036 ; \chi^{2}{ }_{(3650)}$ $=6267.404$ ). The RMSEA (Root Mean Square Error of Approximation) represents an estimate of discrepancy between the model and the data per degree of freedom for the model. Values less than .05 indicate good model fit with those greater than 0.10 representing poor model fit. The SRMR (standardized root mean square residual) is the average standardized residual value derived from fitting the hypothesized variance covariance matrix to that of the sample data. Its value ranges from zero to 1.00 , with a value less than .08 being indicative of a well-fitting model ( $\mathrm{Hu} \&$ Bentler, 1999). Although the reported chi-square $\left(\chi^{2}\right)$ value cannot be regarded as an indicator of model fit per se (Jöreskog, 1971), it does serve well in enabling a comparison of viable competing models. Results of this structure based on Group 1 were found to be as follows: $\mathrm{RMSEA}=0.041$; $\mathrm{SRMR}=$ $0.043 ; \chi_{(3875)}^{2}=7608.941$. That these values were found to be lower for the 5-factor, than for the 4-factor structure, argues in favor of the latter. Factor loadings ranged from .345 to .881 $(M d=.698)$ for Factor $1 ; .305$ to $.599(M d=.478)$ for Factor $2 ; .348$ to $.490(M d=.443)$ for Factor $3 ; .293$ to $.449(M d=$ $.355)$ for Factor 4 , and .253 to $.352(M d=.352)$ for Factor 5.

It is important to that our rationale in not basing selection of factor structure on the more commonly reported KaiserGuttman Criterion (eigenvalues $>1$, and the "scree test"B Although the Kaiser-Guttman criterion is appealing in its simplicity and objectivity, it has been shown to have many serious limitations (Fabrigar et al.,1999). For example, one criticism of the Kaiser-Guttman criterion is its tendency toward over-factoring. A case in point derives from our EFA work here as no less than 20 eigenvalues were found to be $>1$ ! Likewise, the subjectivity of the "scree test has been be faulted in showing no clear definition of what constitutes a "substantial" drop in magnitude of eigenvalues and, indeed, the pattern of eigenvalues may yield no clear substantive drop at all.

\section{Step 2. Confirmatory Factor Analyses (Group 2; n = 584)}

In this second stage of analyses involving Group 2, the same pattern of item loadings for the EFA was restructured as a CFA model, albeit with item selection based on two definitive factor loading cut points: (a) only items having 
EFA loadings of .30 or greater were specified for Factors 1, 2 , and 3 , and (b) only items having loadings of .25 or greater specified for Factors 4 and 5. In total, only 83 items were included in the initial CFA model; five items failed to qualify and two items (R005; R060) cross-loaded on another factor.

Specification of the 5-factor EFA pattern of factor loadings as a CFA model allows for a more rigorous exploration of this structure in several ways. First, in contrast to EFA, the postulated factorial structure can be tested statistically to determine the extent to which this model fits the sample data. Second, based on maximum likelhood (ML) estimation, CFA yields several goodness-of-fit indices that can more definitively assess the extent to which the factorial structure most appropriately represents the sample data. Third, given evidence that the data are non-normally distributed, CFA allows for use of the robust MLM estimator and enables correction of both the $\chi^{2}$ statistic and the indices of model fit (CFI; RMSEA), as well as the standard errors. Fourth, in contrast to EFA, the CFA model provides estimation of item error variance. Finally, CFA provides information on the extent to which the hypothesized factor structure may be misspecified and identifies the degree to which each misfitting parameter contributes to such misfit (For and extensive elaboration of the distinctions between EFA and CFA models, see Byrne, 2005).

As expected, given the limited capability of EFA to provide only minimally generalized model information, results for the initial test of the hypothesized 5-factor CFA model yielded evidence of a very poor fit $(\mathrm{CFI}=.813$; RMSEA $=.043$; SRMR $=.063$ ). The CFI (Comparative Fit Index; Bentler 1990) ranges in value from zero to 1.00 , with a value of 0.90 serving as a cutpoint for minimally acceptable goodness-of-fit. Although the RMSEA and SRMR fell within acceptable ranges, the CFI is indicative of several misspecified parameters in the model.

Given rejection of the hypothesized 5-factor model, we proceeded in an exploratory mode to conduct post hoc analyses as a means of determining areas of model misspecification. Following a review of the modification indices (MIs), this process began by respecifying the model with the parameter having the largest MI freely estimated if, and only if its inclusion was substantively meaningful. In other words, following estimation of each respecified model, the MIs were reviewed and the parameter shown to bring about the largest drop in the overall $\chi^{2}$ value, if determined to be substantively meaningful, was then added to the model and the model again reestimated. Post analytic tests are presented in Table 1.

Post hoc analyses included the testing of 10 respecified models before a marginally acceptable fit to the sample data was determined $\left(\chi_{(1693)}^{2}=3177.142 ; \mathrm{CFI}=.900\right.$; RMSEA $=.039(90 \% \mathrm{CI}=.037 .041) ; \mathrm{SRMR}=.051)$. Given their influence on further refinement of the STCS, it is important to note that these respecified models included 6 error covariances and one cross-loading, which is not surprising given the total number of items comprising this assessment scale. Error covariances are suggestive of overlapping item content, which most typically, reflect item content that asks the same question but in a slightly different way. A crossloaded item represents one that although designed to target one particular factor wants also, to load on another factor. These parameters are typically indicative of item content that is somewhat ambiguous as a consequence of unclear wording structure. Both situations with respect to the STCS are addressed more fully in the Discussion section of this article. A schematic presentation of this final model for the STCS is shown in Figure 1.

Table 1. Summary of Post Hoc Analyses

\begin{tabular}{|c|c|c|c|c|c|c|c|}
\hline Model Description & $\chi^{2}$ & $d f$ & CFI & RMSEA & $90 \% C I$ & $S R$ & $M R$ \\
\hline 1. Hypothesized 5-Factor Model & 6736.824 & 3226 & .813 & .043 & .042 & .045 & .063 \\
\hline $\begin{array}{l}\text { 2. Model } 1 \text { with only items having standardized loadings of } .30 \\
\text { or better included }\end{array}$ & 5382.262 & 2545 & .841 & .044 & .042 & .045 & .059 \\
\hline $\begin{array}{l}\text { 3. Model } 2 \text { with error covariance between Items R067 and } \\
\text { R015 included }\end{array}$ & 5226.694 & 2544 & .849 & .042 & .041 & .044 & .058 \\
\hline $\begin{array}{l}\text { 4. Model } 3 \text { with error covariance between Items R079 and } \\
\text { R038 included }\end{array}$ & 5093.399 & 2543 & .857 & .041 & .040 & .043 & .058 \\
\hline $\begin{array}{l}\text { 5. Model } 4 \text { with only items having standardized loadings of .6 } \\
\text { or higher for F1 and only } .3 \text { or higher for F2 to F5 }\end{array}$ & 3502.182 & 1699 & .879 & .043 & .041 & .045 & .057 \\
\hline $\begin{array}{l}\text { 6. Model } 5 \text { with error covariance between Items R086 and } \\
\text { R043 included }\end{array}$ & 3437.801 & 1698 & .883 & .042 & .040 & .044 & .057 \\
\hline $\begin{array}{l}\text { 7. Model } 6 \text { with error covariance between Items R061 and } \\
\text { R060 included }\end{array}$ & 3369.346 & 1697 & .888 & .041 & .039 & .043 & .056 \\
\hline 8. Model 7 with Item R080 ross-loaded on F1 & 3295.716 & 1696 & .893 & .040 & .038 & .042 & .052 \\
\hline $\begin{array}{l}\text { 9. Model } 8 \text { with error covariance between Items R030 and } \\
\text { R002 included }\end{array}$ & 3250.280 & 1695 & .896 & .040 & .038 & .042 & .051 \\
\hline $\begin{array}{l}\text { 10. Model } 9 \text { with error covariance between Items R098 and } \\
\text { R099 included }\end{array}$ & 3208.852 & 1694 & .898 & .039 & .037 & .041 & .051 \\
\hline $\begin{array}{l}\text { 11. Model } 10 \text { with error covariance between items R019 and } \\
\text { R016 included- }\end{array}$ & 3177.142 & 1693 & .900 & .039 & .037 & .041 & .051 \\
\hline
\end{tabular}

Note. CFI = Comparative Fit Index; RMSEA = Root Mean Square Error of Approximation 


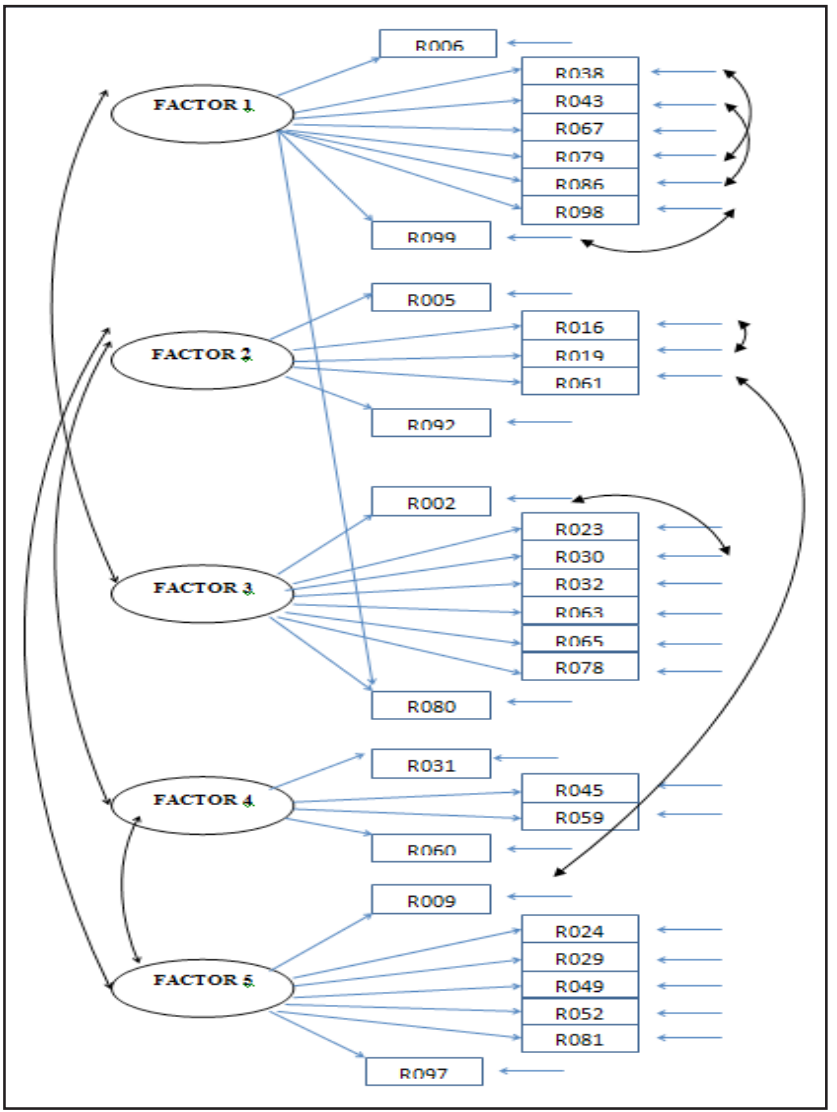

Figure 1. 5-Factor Structure of the STCS Short Version

It is important to note, however, that due to the large number of items (60), albeit the restriction of space allotted to one page, a reduced number of items associated with Factors 1 and 2 are included. Specifically, for each of these two subscales, only those items having error covariances are included (e.g., F1 - R038-R098), in addition to the first and last item of each scale (e.g., F1 - R006; R099). In the interest of clarity, the first and last item for each of the five subscales is located closest to the related factor. With respect to Factors 3, 4, and 5, all subscale items are included (e.g., F4 - R031, R045, R059, R060).

The single-headed arrows radiating from each factor to its congeneric set of related items represent the regression of each item onto the target factor. Relatedly, the single-headed arrow leading from Factor 1 to Item R080 represents the cross-loading of this item onto Factor 1; as shown in Figure 1, the original targeted factor for this item is Factor 3. In contrast, the smaller single-headed arrows associated with each item, as shown on the right side of the figure represent error variance, which reflects on the impact of measurement error.

Finally, the curved two-headed arrows represent covariances (i.e., correlations when based on standardized estimates); only those found to be statistically significant are included here. The double-headed arrows on the left side of the figure represent the factor correlations. As such results revealed correlations between Factors 1 and 3; Factors 2 and 4; Factors 2 and 5; and Factors 4 and 5. The curved double-headed arrows associated with the item error variances represent error covariances (i.e., error correlations based on standardized estimates). As noted earlier in text, results derived from the post hoc analyses revealed 6 error covariances; shown here in the order in which they appear are (starting from the top): R038/R079; R043/R086; R098/ R099; R016/R019; R061/R060; R002/R030.

\section{Step 3. Cross-validation of Final CFA Model (Group 3; $\mathrm{n}=\mathbf{5 8 2}$ )}

Having determined the best fitting CFA model, the next step was to cross-validate this model for Group 3. Importantly, in cross-validation, no model respecifications for the validation sample are permitted. Two sets of tests were conducted. First, we tested the fit of the final CFA model on Group 3 data. Second, working within the framework of a multigroup model, we tested for the invariance of the factor loadings and factor correlations across Group 2 (the calibration group) and Group 3 (the validation group).

Model validation for Group 3. Results of model goodness-of-fit statistics for Group 3 data were as follows: CFI $=.900 ;$ RMSEA $=.039,90 \%$ CI .037 .041 ; SRMR $=$ .050 , thereby serving to validate this model for the Group 3 .

Tests for Invariance across Group 2 and Group 3. In testing for invariance (i.e., equivalence) across groups, the two sets of data are analysed simultaneously. Four sets of tests were conducted in testing across these calibration and validation groups. First, we tested for goodness-of-fit for what is termed the "configural" model, a multigroup model for which no equality constraints are imposed. This initial test simply assesses the appropriateness of the same factorial pattern and structure across the groups. Second, we tested for the invariance of factor loadings (including the crossloadings) across Groups 2 and 3 through the placement of equality constraints on all factor loadings. That is, the factor loadings for Group 3 were specified as being equivalent to those of Group 2. Third, we tested for the invariance of all factor loadings plus all specified error covariances, with equality constraints being placed on these parameters, Finally, we tested for the invariance of factor loadings, error covariances, and latent factor correlations in combination. That is, equality constraints were imposed on all of these parameters such that those in Group 3 were equated with those in Group 2. For a more extensive elaboration of tests for multigroup equivalence see (Byrne, 2006, 2008, 2010, 2012.)

In reviewing goodness-of-fit results for the configural model, which essentially represents the model specification for the final best-fitting CFA model for each of Group 2 and Group 3 within the framework of a multigroup structure, the fit indices basically replicated those of each model tested separately. These results substantiate the validity of the factorial pattern across Groups 2 and 3.

In testing for evidence of invariant factor loadings, the first comparison is made between the fit of Model 1 (configural model) in which no equality constraints were imposed and Model 2, in which these constraints were imposed on all factor loadings (including the cross-loadings). In determining the extent to which invariance holds across the groups, it is customary to take the difference in the $\chi 2$ values of the two models being compared as this $\chi 2$-difference value 
is distributed as $\chi^{2}$ with the matching difference in degrees of freedom. It is important to note that due to the need to base analyses on the robust ML estimator (as noted earlier), this difference must be computed through application of a specific formula, which can be found in Byrne (2012). This corrected difference in fit between the fit of the configural model and the more restrictive Model 2 was found to be nonsignificant, thereby supporting total invariance of all factor loadings (including cross-loadings) across Groups 2 and 3.

Because the subsequent Models 2, 3, and 4 are more restrictive and thus nested in the configural model, the next comparison involved Model 3 in which equality constraints were maintained on all the factor loadings in addition to the error covariances. Once again, this comparison revealed no statistically significant differences thereby arguing for the invariance of these factor loadings and error covariances across Groups 2 and 3.

The final test for invariance involved a comparison between the configural model and Model 4 in which equality constraints were placed on all factor loadings, all error covariances and all latent factor covariances. Once again, this comparison was found to be nonsignificant, thereby serving to support the total invariance of the final best-fitting CFA model across the calibration and validation groups. These results are summarized in Table 2.

\section{Step 4. Development of a Short Version of the STCS}

Taking into account the EFA results, followed by the more rigorous CFA results and subsequent excellent results of the tests for invariance across Groups 2 and 3, we propose that a viable short version of the STCS can be based on the final CFA model and comprises only 60 of the original 100 items. Items related to each factor (i.e., subscale), together with their related alpha internal consistency reliability value based on the full sample, as well as for Groups 2 and 3 are reported in Figure 2.

Table 2. Tests for Invariance of best-fitting CFA model across Group 2 and Group 3: Goodness of Fit Statistics

\begin{tabular}{|c|c|c|c|c|c|c|c|c|c|c|}
\hline Model & $\Delta^{2}$ & $d f$ & CFI & $R M S E A$ & $R M S E A$ & 90\% C.I. & SRMR & $\Delta \chi^{2}$ & $\Delta d f$ & $\begin{array}{c}\text { Statistical } \\
\text { Significance }\end{array}$ \\
\hline $\begin{array}{l}1 \text { Configural model No equality } \\
\text { constraints imposed }\end{array}$ & 6582.102 & 3502 & .900 & .039 & .037 & .040 & .051 & ---- & & ---- \\
\hline $\begin{array}{l}2 \text { Factor loadings and } 2 \\
\text { crossloadings constrained equal } \\
\text { across groups }\end{array}$ & 6626.603 & 3564 & .901 & .038 & .037 & .040 & .052 & 35.494 & 62 & NS \\
\hline $\begin{array}{l}3 \text { Factor loadings, } 2 \text { cross- } \\
\text { loadings, and error covariances } \\
\text { constrained equal across groups }\end{array}$ & 6640.552 & 3571 & .900 & .038 & .037 & .040 & .052 & 51.375 & 69 & NS \\
\hline $\begin{array}{l}4 \text { Factor loadings, } 2 \\
\text { cross-loadings, error } \\
\text { covariancesand latent factor } \\
\text { correlationsconstrained equal } \\
\text { across groups }\end{array}$ & 6649.948 & 3581 & .900 & .038 & .037 & .040 & .053 & 60.690 & 79 & NS \\
\hline
\end{tabular}

Notes. CFI = Comparative Fit Index $;$ RMSEA $=$ Root Mean Square Error of Approximation; C.I. = confidence interval; SRMR $=$ Standardized Root Mean Square Residual; $\Delta \chi^{2}=$ corrected difference in MLM chi square values; $\Delta \mathrm{df}=$ difference in degrees of freedom

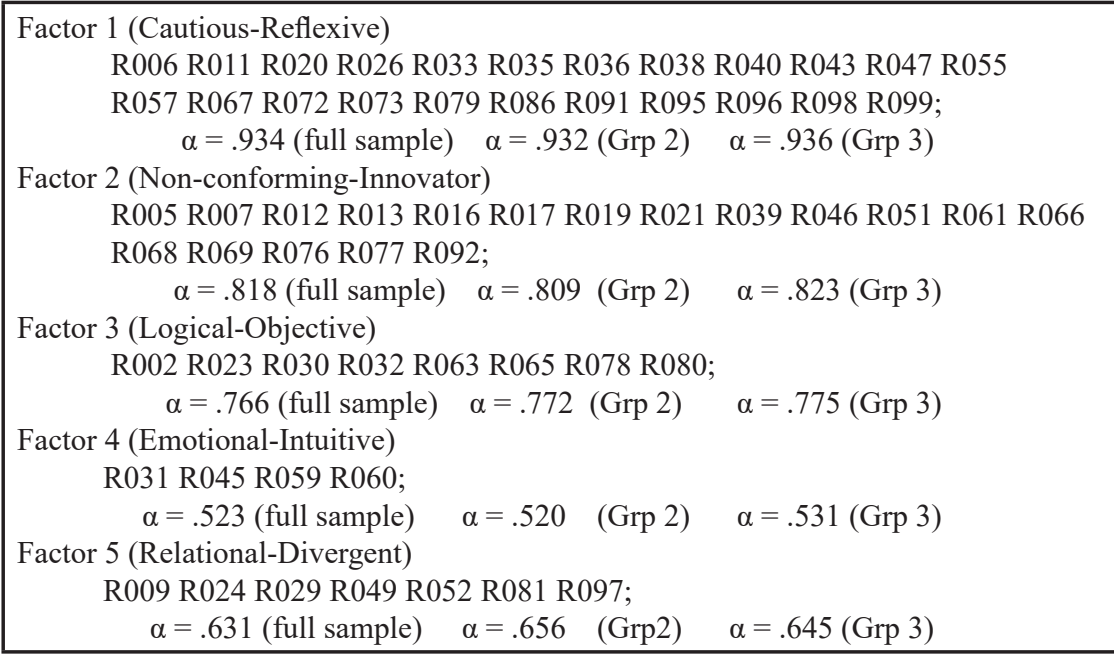

Figure 2. Proposed Factorial Structure of the STCS Short Version 


\section{Discussion}

Styles can be defined as individual preferences of processing information and are considered to be partly fixed and relatively stable (Peterson et al., 2009). The concept of cognitive styles has been well discussed in the literature and is conceptualized under an integrated theory considering styles derived from a biopsychosocial approach (Zhang \& Sternberg, 2006). However, the notion of creative styles is still unclear, as they need to be distinguished from intellectual abilities, divergent thinking, problem solving processes or personality characteristics (Kirton, 1999; Puccio et al., 2007; Selby at al., 2007).

Measuring creative and thinking styles, therefore, can be considered a definite challenge. There is a need to search for rigorous and validated procedures to analyze thinking and styles instruments, as they nearly always tend to be presented as grounded only in theory. Evidence of internal validity appears to be the weakest criterion with respect to styles measures (Coffield, et al., 2004), thus indicating the need for more studies to meet the rigorous criteria set forth in the Standards for Educational and Psychological Testing (AERA, APA, \& NCME, 2014).

Addressing these concerns, the intent of this study was twofold: (a) to reanalyze the STCS Wechsler, 2006), which has previously been validated using PCA, and (b) based on these comprehensive analyses, to propose a shorter, albeit psychometrically viable version of the scale. Turning first to the initial aim of the study, we noted that according to the original research, 5 styles could be obtained from STCS: Cautious-Reflexive, Non-Conforming-Innovative, LogicalObjective, Emotional-Intuitive and Relational-Divergent. Subsequently, however the number of styles derived from the STCS has been questioned in the country of Portugal, with two studies, one in Lisbon and the other in Island of Madeira, where only three to four styles were observed (Garces et al., 2014; Nogueira et al., 2015). These results demonstrated the need to reanalyze the original sample through more rigorous CFA procedures.

Our CFA results validated the 5 -styles model representative of the STCS: 1) Cautious-Reflexive; 2) Non-conformingInnovative; 3) Logical-Objective; 4) Intuitive-Emotional, 5) Divergent-Relational. This information is important as these styles were found to be related to real life creative achievements as well as to Torrance's creativity tests (Wechsler et al., 2012). Thus, there is validity evidence for the STCS as confirmed by conventional as well as updated and more rigorous factor analytic procedures. In addition, reliability indexes for these factors were very similar to those obtained in the original study, thus indicating a consistency of findings.

The item composition for each factor represented the concept as initially measured, with one minor exception. Specifically, Items 31 and 60 (importance given to imagination; need to question rules of thinking and behavior, respectively) were added to Factor 4 (Intuitive-Emotional), albeit they were not included in the earlier PCA investigation. In addition, it is interesting to observe our findings of one cross-loading and 6 error covariances pertinent to these factors, information that is not possible to obtain using EFA and PCA procedures (see Byrne, 2005 for a delineation of these differences from CFA). We turn first to the crossloading (see Figure 1). Results indicated the loading of R080 onto Factor 1 (Cautious-Reflexive), in addition to Factor 3 (Logical-Objective), its target factor, which can be interpreted as reflecting a preference for tasks with predetermined solutions.

Let's turn now to our finding of 6 error covariances. These parameters are indicated in Figure 1 and represent systematic, rather than random measurement error. Typically, error covariances are indicative of overlapping item content (For more detailed explanation, see Byrne, 2006, 2010, 2012). As shown in Figure 1 pertinent to Factor 1 (CautiousReflexive), there are error covariances between R038 and R079 measuring objectivity and practicality, R043 and R086 measuring lack of confidence and insecurity in decisionmaking, R098 and R099 measuring decision need and human rights considerations. Turning to Factor 2 (Non-ConformingInnovative), there are two error covariances; one between R016 and R019 measuring self-confidence and optimistic and the other between R061 for this scale and R060 measuring the need to defend one's ideas and to question rules for Factor 4 (Emotional-Intuitive). Finally, there is one error covariance associated with Factor 3 (Logical-Objective), which involves R002 measuring preference to work following instructions and R030 measuring preferences to work with rules and methods.

The three error covariances associated with Factor 1, as well as two within-scale error covariances - one associated with Factor 2 and the other with Factor 3 - reflect some degree of redundancy, which is not necessarily a negative feature of these two scales as noted earlier. Nonetheless, this information is valuable information suggesting that reconstruction of content related to these items may be worthy of consideration in future revisions of the STCS. Of more concern is the cross-loading of Item 80 on Factor 1, as well as the error covariation between R061 loading on Factor 2 and R060 loading on Factor 4. In both cases, the item content needs to be revised such that it more appropriately measures the factor for which it was designed.

We believe that a second important and practical contribution of this study derives from our second objective, which was to propose a shorter yet psychometrically valid version of the STCS based on 60, rather than on 90 items. Given that time allotments for test administration under various situations is typically short, not only in organizational (Mundin \& Wechsler, 2007) but also in educational settings (Alencar \& Fleith, 2016; Nakano et al., 2010), it seems reasonable to assume that this shorter version of the STCS can contribute importantly to reducing the risk of participants' fatigue yet can still provide valid and reliable information on thinking and creative styles.

In conclusion, we believe that the reanalyses presented in this study reaffirmed that there are different ways of thinking and behaving creatively, as demonstrated by Wechsler's previous validity studies (Wechsler, 2006; Wechsler et al., 2012). As is evident from a review of the cross-cultural literature, values and ways of expressing creative styles can vary substantially across cultures, which can probably explain the differences determined from use of the STCS in Portugal and its Island of Madeira (see Garces et al., 2014; Nogueira 
et al., 2015). Further studies are needed in other cultural contexts, using the same statistical procedures, in order to conclude the extent to which the number and structure of creative and thinking styles replicate our findings. These studies could make an important contribution to the field of creativity, as styles reflect preferences that can be influenced by both cultural values and individualistic characteristics.

\section{References}

Alencar, E. M.L.S., \& Fleith, D. (2016), Relationships between motivation, cognitive styles and perception of teaching practices for creativity. Estudos de Psicologia (Campinas), 33(3) 503-513. doi.org/10.1590/1982-02752016000300013

American Educational Research Association, American Psychological Association, \& National Council for Measurement in Education. (2014). Standards for educational and psychological testing. Washington DC: American Psychological Association

Bentler, P. M. (1990). Comparative fit indexes in structural models. Psychological Bulletin, 107, 238-246. doi: http://dx.doi. org/10.1037/0033-2909.107.2.238

Byrne, B. M. (2005). Factor analytic models: Viewing the structure of an assessment instrument from three perspectives. Journal of Personality Assessment, 85, 17-30. doi: http://dx.doi. org/10.1207/s15327752jpa8501_02

Byrne, B. M. (2006). Structural equation modeling with EQS: Basic concepts, applications, and programming (2nd Edition). Mahwah NJ: Erlbaum.

Byrne, B. M. (2008). Testing for multigroup equivalence of a measuring instrument: A walk through the process. Psichothema, 20, 872-882.

Byrne, B. M. (2010). Structural equation modeling with Amos: Basic concepts, applications, and programming (2nd Edition). New York: Taylor \& Francis/Routledge.

Byrne, B. M. (2012). Structural equation modeling with Mplus: Basic concepts, applications, and programming. New York: Taylor \& Francis/Routledge

Cassidy, S. (2004). Learning styles: An overview of theories, models and measures. Educational Psychology, 24(4), 419-444.

Coffield, F. Moseley, D., Hall, E., \& Ecclestone, K. (2004). Should we use learning styles? What research has to stay to practice., Wiltshire: Townbridge.

Csikszentmihalyi, M. (2009). Implications of a systems perspective for the study of creativity. In R. Sternberg (Ed.), Handbook of Creativity (pp. 313-338). Cambridge: Cambridge University Press.

Cools, E. (2009). A reflection on the future of cognitive style field. A proposed research agenda. Reflecting Education, 5(2), 19-34.

Devellis, R. F. (2012). Scale development: Theory and application (3rd edition). Los Angeles: Sage

Fabrigar, L. R., Wegener, D. T., MacCallum, R. C., \& Strahan, E. J. (1999). Evaluating the use of exploratory factor analysis in psychological research. Psychological Methods, 4, 272-299. doi: http://dx.doi.org/10.1037/1082-989X.4.3.272

Garces, S., Pocinho, M., Wechsler, S., M., \& Neves, S. N. (2014). Estilos de pensar e criar na Região Autonoma da Madeira. Revista Interamericana de Diagnóstico y Evaluación Psicológica-RIDEP, 38(2), 55-69.
Grigorenko, E. L. (2009). What is so stylish about styles? Comments on the genetic etiology of intellectual styles. In L. F. Zhang \& R. J. Sternberg (Eds.), Perspectives on the nature of intellectual styles (pp 233-251). New York: Springer.

Hennessey, B., \& Amabile, T. (2010). Creativity. Annual Review of Psychology, 61, 569-598. doi: 10.1146/annurev. psych.093008.100416

Hu, L-T, \& Bentler, P. M. (1999). Cutoff criteria for fit indexes in covariance structure analysis: Conventional criteria versus new alternatives. Structural Equation Modeling, 6, 1-55. doi: http://dx.doi.org/10.1080/10705519909540118

Isaksen, S. G. (2004). The progress and potential of the creativitylevel distinction: Implications for research and practice. In W. Haukedal \& F. Kuvaas (Eds.), Creativity and problemsolving in the context of business management (pp. 40-71). Bergen, Norway: Tagbookforlaget

Isaksen, S. G., Kaufman, A. H., \& Bakken, B. T. (2014). An examination of the personality constructs underlying dimensions of the creative problem solving style. Journal of Creative Behavior, 0, 1-18. doi: http://dx.doi.org/10.1002/ jocb. 75

Isaksen, S. G., Wilson, G. V., \& Lauer, K. J. (2003). An examination of the relationship between personality type and cognitive style. Creativity Research Journal, 15, 343-354. doi: http://dx.doi. org/10.1207/S15326934CRJ1504_4

Jöreskog, K.G. (1971). Statistical analysis of sets of congeneric tests. Psychometrika, 36, 109-133. doi: http://dx.doi.org/10.1007/ BF02291393

Kaufman, J. C. \& Baer, J. M. (2005). Creativity across domains: Faces of the muse. Hillsdale, N. J. Erlbaum.

Kirton, M. J. (1989). Adaptors and innovators: Styles of creativity and problem solving. London, UK: Routledge

Kirton, M. J. (1999). KAI-Kirton Adaptation-Innovation Inventory. Manual (3rd. ed.). Berkhamstead. UK: Occupational Research Center.

Miller, P. (2001). Learning styles: The multimedia of the mind. Erich Research Report ED451140.

Mundin, M. C., \& Wechsler, S. M. (2007). Estilos de pensar e criar em gerentes e subordinados [Managers and assistants 'thinking and creative styles]. Boletim de Psicologia, LVII, 15-32.

Muthén, L. K., \& Muthén, B.O. (1998-2012). Mplus User's Guide (7th. Ed.). Los Angeles, CA: Muthén \& Muthén.

Nakano, T. C., Santos, E., Zavariz, S. F., Wechsler, S. M., \& Martins, E. (2010). Estilos de pensar e criar em universitarios da área de humanas e ciencias sociais aplicadas: Diferenças de gênero e curso [Styles of thinking and creating of college students majoring in human and social sciences: Gender and course differences]. Psicologia, Teoria e Pratica, 12, 120-134.

Nielsen, T. (2012). A historical review of the styles literature. In L.F. Zhang, R. Sternberg, \& Rayner, S. (Eds.), Handbook of intellectual styles (p.21-46). New York: Springer.

Nogueira, S. I., Almeida, L. S., Garces, S., Pocinho, M., \& Wechsler, S. M. (2015). The style TROIKA model (STM). The Journal of Creative Behavior, 0 ,1-19, doi:10.1002/jocb.81

Peterson, E. R., Rayner, S. G., \& Armstrong, S. J. (2009). Researching the psychology of cognitive style and learning style: Is there really a future? Learning and Individual Differences, 19, 518-523. doi:10.1016/j.lindif.2009.06.003

Puccio, G. J., Murdock, M. C., \& Mance, M. (2007). Creative leadership: Skills that drive change. Thousands Oak, CA: Sage 
Rayner, S., \& Peterson, E. R. (2009). Reaffirming styles as an individual difference: Toward a global paradigm or knowledge diaspora. In L. F. Zhang \& R. Sternberg (Eds.), Perspectives on the nature of intellectual styles (p. 107-134). New York: Springer.

Roodenburg, J. (2003). Cognitive style: A psycholexically-derived personality centred-model. European Journal of Personality, 17, 119-141. doi:10.1002/per.470

Runco, M. A., \& Jaeger, G. J. (2012). The standard definition of creativity. Creativity Research Journal, 24(1), 92-96. doi: 10.1080/10400419.2012.650092

Selby, E. C., Treffinger, D. J., \& Isaksen, S. G. (2007). VIEW: An assessment of problem solving style. Technical Manual (2nd ed.). Sarasota, FL: Center for Creative Learning

Sternberg, R. J., \& Grigorenko, E. L. (2001). A capsule history of theory and research on styles. In R. J. Sternberg \& I. F. Zhang (Eds), Perspectives on thinking, learning and cognitive styles (pp. 1-22). Mahwah, NJ: Erlbaum.

Sternberg, R. J., Grigorenko, E. L., \& Singer, J. L. (2004). Creativity: From potential to realization. Washington, DC: American Psychological Association
Sternberg, R. J., \& Lubart, T. I. (2009). The Concept of Creativity: Prospects and Paradigms. In R. Sternberg (Ed.), Handbook of Creativity (pp. 3-15). Cambridge: Cambridge University Press.

Torrance, E. P. (1988). The nature or creativity as manifest on its testing. In R. J. Sternberg (Ed.), The nature of creativity ( $\mathrm{p}$. 43-75). New York: Cambridge University Press.

Wechsler, S. (2006). Estilos de Pensar e Criar [Thinking and Creating Styles]. Duo Paper / LAMP: Campinas: Sao Paulo

Wechsler, S., Vendramini, C., \& Oakland, T. (2012). Thinking and creating styles: A validity study. Creativity Research Journal, 24(2), 235-242. doi: doi.org/10.1080/10400419.2012.677359

Zhang, L. F. (2013) The malleability of intellectual styles. New York: Cambridge University Press

Zhang, L. F., \& Sternberg, R. (2006). The nature of intellectual styles. New York: Psychology Press

Zhang, L.F., \& Sternberg, R. J., \& Rayner, S. (2012). Handbook of intellectual styles: Preferences in cognition, learning and thinking. New York: Springer.

Recebido em 22.07.2015

Primeira decisão editorial em 18.05.2016

Versão final em 25.07.2016

Aceito em 27.08.2016 